ORIGINAL ARTICLE

\title{
Does weaning influence growth and health up to 18 months?
}

\author{
J B Morgan, A Lucas, M S Fewtrell
}

Arch Dis Child 2004;89:728-733. doi: 10.1136/adc.2003.036137

See end of article for authors' affiliations .....................

Correspondence to: Dr J B Morgan, School of Biomedical and Molecular Sciences, University of Surrey, Guildford, Surrey GU2 7XH, UK; i.morgan@ surrey.ac.uk

Accepted

22 December 2003 Background: National and international recommendations for the age of introducing solid foods
(weaning) are founded on insufficient evidence and little is known about the short and medium term consequences associated with early or late weaning.

Aims and Methods: Data from over 1600 infants from five prospective randomised trials conducted in the UK between 1993 and 1997 were used to determine the influence of weaning $\leqslant 12$ weeks or $>12$ weeks on growth and health outcomes (diarrhoea and vomiting, lower respiratory chest infections, atopy, sleep patterns) up to 18 months post-term, in term appropriate for gestational age (AGA), term small for gestational age (SGA), and preterm infants.

Results: Term infants weaned $\leqslant 12$ weeks were heavier at 12 weeks of age than those weaned after 12 weeks, but showed slower gain in weight, length, and head circumference between 12 weeks and 18 months than those weaned after 12 weeks; by 18 months, there were no significant differences in size between the two groups. A similar pattern was seen in preterm infants. Breast fed term infants were more likely to be sleeping though the night at 9 months if they were weaned before 12 weeks. No weaning effects or interactions were observed for health outcomes.

Conclusions: We found little evidence that weaning before or after 12 weeks influences health outcomes up to 18 months. Early weaned infants were larger at 12 weeks than later weaned infants but the growth trajectories of the two groups "converged" by 18 months. These findings do not exclude the later emergence of programmed effects of weaning practices.
$\mathrm{T}$ here is a lack of sound evidence from appropriately designed studies on the effects of weaning (introduction of solid foods) on outcomes such as growth and morbidity. This is surprising, given the radical shift in the dietary pattern of infants which occurs over a relatively short period of time at around 12-17 weeks of age, as a result of the weaning process. This shift is from a diet comprising a high fat, low protein single food, breast or formula milk, to a more complex mixture of foods, which is relatively high in protein with a low to medium fat and fibre content. Increased exposure of infants to bacterial and chemical contamination, and to food allergens, coincides with this dietary change. Most studies relating to infant nutrition have focused on milk feeding, and the effect of introducing solid foods has been relatively neglected.

Under the auspices of the World Health Organisation (WHO), Kramer and Kakuma, ${ }^{1}$ published a systematic review of the optimal duration of exclusive breast feeding in the full term infant. The main conclusions were that, depending on the outcome measured, exclusive breast feeding to 6 months could be beneficial (reduced gastrointestinal infection), neither beneficial or harmful (atopic eczema, asthma), or possibly harmful (compromised iron status). The authors specifically highlighted the lack of good data and the need for further research in this field. However, despite the lack of good scientific evidence, in 2001 the World Health Assembly revised the infant feeding recommendation for exclusive breast feeding from 4-6 months to 6 months. This recommendation has been adopted by the $\mathrm{WHO},{ }^{2}$ and more recently by the UK Department of Health.

We have used data from five UK cohorts to examine the impact of the age of weaning on growth and health outcomes. These data were used to test the hypotheses that early weaning ( $\leqslant 12$ weeks as opposed to $>12$ weeks) is associated with more rapid growth, higher rates of atopy and gastroenteritis, but longer sleep duration up to 18 months post-term, independent of type of milk feeding, gender, and potential socioeconomic confounding factors.

\section{METHODS}

\section{Subjects}

Data from 1694 infants from five prospective randomised dietary trials were used. Two trials involved term AGA infants, ${ }^{3}{ }^{4}$ one trial involved term SGA infants (birth weight $<10$ th centile for gestational age and sex, $\left.{ }^{5}\right)$, and two trials involved preterm infants ( $<37$ weeks gestation, birth weight $<2000$ g; see Lucas and colleagues ${ }^{6}$ and unpublished data). Details of the trials have been previously described. ${ }^{7}$ All trials included a randomised comparison of a dietary intervention, and all but one (preterm study B) included a reference group of breast fed infants. These infants were predominantly breast fed for at least six weeks. In the case of the preterm cohort, they were allowed up to $2 \mathrm{oz}$ of infant formula per day.

Information on feeding practices was collected prospectively in all but the term AGA iron study. At 6, 12, and 26 weeks post-term, mothers were asked if they had started their infant on solid foods. In one study (AGA term I) infants were recruited at 9 months, and mothers were asked retrospectively to recall the age of the infant when solids were introduced.

Growth data (body weight, supine length, head circumference, and triceps and subscapular skinfolds) were collected at 12 and 26 weeks, and 9 and 18 months (post-term in the case of premature infants). In the case of preterm breast fed infants, the majority were followed up until 9 months post-term, but few $(n=24)$ were seen at 18 months. For this

Abbreviations: AGA, appropriate for gestational age; LRTI, lower respiratory tract infection; SGA, small for gestational age 
reason, the main growth analyses on the preterm cohorts were performed at 9 rather than 18 months post-term, although findings up to 18 months are also reported.

Data on morbidity were collected at 26 weeks, 9 months, and 18 months of age. Mothers were asked the number of episodes of lower respiratory tract infections (LRTI) requiring antibiotics since the last visit (thus, for example, in the case of the 26 week visit this would have been since 12 weeks); number of episodes of gastroenteritis (diarrhoea plus vomiting); and the presence of asthma (diagnosed by GP or paediatrician); eczema (including both small patches and more widespread areas); and wheeze (present or absent). For the purpose of the analyses presented here, these conditions were coded as present or absent at each visit.

Parents were asked the usual time the infant was put to bed and the time that he or she woke; the number of hours of sleep was then calculated at each time point. The number of times the infant usually woke in the night was also recorded at each visit. For the purposes of data analysis infants were coded as either sleeping throughout the night or not.

For each study, data were also collected at baseline on socioeconomic status (based on the UK Registrar General's classification), maternal educational achievements (recorded on a five point scale ranging from no qualifications to higher professional qualifications as described previously), ${ }^{8}$ parity, and parental smoking (during the second and third trimesters).

\section{Statistical analyses}

Databases for the individual studies were merged into one database. Data for preterm and term infants were analysed separately.

Outcome measures were as follows:

- Weight, length, head circumference, and skinfold thicknesses at 18 months (9 months for preterm infants) adjusted for the measurement at 12 weeks.

- The proportion of infants who had experienced an episode of LRTI between 12 weeks and 9 months and between 9 and 18 months.

- The proportion of infants with one or more episodes of gastroenteritis between 12 weeks and 9 months and between 9 and 18 months.

- The proportion of infants with asthma, wheeze, and eczema at 9 and 18 months.

- The total number of hours of sleep per night at 26 weeks, and 9 and 18 months.

- The proportions reported as waking at night, at 26 weeks, and 9 and 18 months.

Categorical variables were analysed by $\chi^{2}$ test. Continuous variables were analysed using analysis of covariance. For each continuous outcome measure, the effect of weaning before or after 12 weeks was examined, after adjusting for type of milk feeding (predominantly breast fed for at least six weeks, versus formula fed), gender, and cohort (term AGA or term SGA). We tested for interactions between weaning and the other factors. Where an effect of weaning was identified, the models were further adjusted for potential confounding factors (social code, level of mother's education, maternal age, birth order, and parental smoking). Results were considered significant if $\mathrm{p}<0.05$. No adjustment was made for multiple testing and this should be taken into account when considering the results.

\section{RESULTS}

Demographic and other details of the five cohorts have been previously reported. ${ }^{7}$

\section{Term infants}

Weaning before or after 12 weeks

Table 1 shows the influence of early $(\leqslant 12$ weeks) or later (>12 weeks) weaning on growth outcomes. Weight, length, and head circumference gain between 12 weeks and 18 months were significantly greater in infants weaned after 12 weeks, and these differences remained significant when the models were adjusted for socioeconomic confounding factors ( $p=0.020$ for weight, $p=0.011$ for length, $p=0.04$ for head circumference). However, infants who were weaned $\leqslant 12$ weeks were heavier $(5.68 \mathrm{~kg} v 5.45 \mathrm{~kg}, \mathrm{p}<0.001)$, longer $(59.04 \mathrm{~cm} v 58.56 \mathrm{~cm}, \mathrm{p}=0.01)$, and had larger head circumference $(40.22 \mathrm{~cm} v 39.81 \mathrm{~cm}, \mathrm{p}<0.001)$ at 12 weeks of age compared with infants weaned after 12 weeks. Between 12 weeks and 18 months growth converged in the two groups and no significant differences were apparent at 18 months, suggesting the faster growth of infants weaned after 12 weeks represents "catch up". Interestingly, while weight gain and length gain between 12 weeks and 9 months were also greater in later weaned infants, the differences were smaller and did not reach significance for length (data not shown).

Infants weaned before 12 weeks slept for significantly longer at both 9 and 18 months post-term (table 1 ), but this effect was no longer significant $(p=0.07)$ after adjusting for confounding factors. Breast fed infants were more likely to sleep through the night at 9 months if they had started solids before 12 weeks $(p=0.01)$, but this effect was not present in formula fed infants.

There was no effect of the age of weaning on the proportions of term infants developing atopy, LRTI, or gastroenteritis. By 9 months, $25 \%$ of infants were reported as having eczema, $3.8 \%$ asthma, and $20 \%$ had had at least one episode of diarrhoea. By 18 months, 30.8\% had eczema, $8 \%$ had asthma, and $22 \%$ had had at least one episode of diarrhoea since the 9 month visit.

In a univariate analysis, males were weaned earlier than females in term infants, though this was just outside the 5\% level of significance $\left(54.1 \% \vee 45.9 \%\right.$ respectively, $\chi^{2}$ test, $\mathrm{p}=0.051$ ). When adjusted for weight, in a multivariate analysis, gender was not a significant predictor of weaning age. ${ }^{7}$

\section{Milk feeding}

At 12 weeks, breast fed infants were lighter than formula fed infants, although length and head circumference were not significantly different. Weight gain between 12 weeks and 9 months did not differ between breast and formula fed infants. However, weight, length, head circumference, and triceps skinfold thickness gain between 12 weeks and 18 months were greater in the breast fed subjects compared with the formula fed term infants (table 2). Differences for weight and head circumference gain remained when the model was adjusted for socioeconomic factors $(p=0.002$ for weight, $\mathrm{p}=0.001$ for head circumference).

Formula fed infants slept for significantly longer at 9 months than breast fed infants (table 2). This effect remained significant after the model was adjusted for confounding factors $(p=0.04)$. Formula fed infants were also significantly more likely to sleep through the night at 9 months than breast fed infants. Differences in sleep duration at 26 weeks and 18 months were not significant.

No effects of milk feeding were observed for atopy (eczema, wheeze, asthma), LRTI, or gastroenteritis.

\section{Gender}

Table 3 shows the influence of gender. Boys were significantly heavier and longer than girls at 12 weeks. Fifty seven per cent of boys were weaned by 12 weeks compared to $52 \%$ of girls $(p=0.051)$. Weight, length, and head circumference 
Table 1 Influence of early ( $\leqslant 12$ weeks) or late ( $>12$ weeks) weaning on growth and sleep patterns; measurements at 9 months in preterm infants and 18 months in term infants adjusted for measurements at 12 weeks*

\begin{tabular}{|c|c|c|c|c|c|c|c|c|c|c|c|c|c|c|}
\hline & \multicolumn{7}{|c|}{ Preterm infants } & \multicolumn{7}{|c|}{ Term infants } \\
\hline & \multicolumn{3}{|c|}{ Weaned $\leqslant 12$ weeks } & \multicolumn{3}{|c|}{ Weaned $>12$ weeks } & \multirow[b]{2}{*}{$\mathbf{p}$} & \multicolumn{3}{|c|}{ Weaned $\leqslant 12$ weeks } & \multicolumn{3}{|c|}{ Weaned $>12$ weeks } & \multirow[b]{2}{*}{$\mathbf{p}$} \\
\hline & $\mathrm{n}$ & Mean & SE & $\mathbf{n}$ & Mean & SE & & $\mathbf{n}$ & Mean & SE & $\mathbf{n}$ & Mean & SE & \\
\hline Weight gain $(\mathrm{kg})$ & 365 & 8.25 & 0.05 & 102 & 8.27 & 0.07 & NS & 350 & 10.7 & 0.05 & 326 & 10.9 & 0.05 & 0.001 \\
\hline Length gain $(\mathrm{cm})$ & 362 & 70.3 & 0.16 & 102 & 70.6 & 0.2 & NS & 350 & 80.8 & 0.14 & 327 & 81.4 & 0.13 & 0.01 \\
\hline $\begin{array}{l}\text { Head circumference } \\
\text { gain }(\mathrm{cm})\end{array}$ & 364 & 45.8 & 0.08 & 102 & 45.8 & 0.12 & NS & 352 & 48.0 & 0.06 & 328 & 48.2 & 0.05 & 0.02 \\
\hline $\begin{array}{l}\text { Triceps skinfold } \\
\text { gain (mm) }\end{array}$ & 364 & 8.68 & 0.17 & 102 & 8.61 & 0.23 & NS & 349 & 8.9 & 0.13 & 327 & 8.8 & 0.12 & NS \\
\hline $\begin{array}{l}\text { Subscapular } \\
\text { skinfold gain (mm) }\end{array}$ & 364 & 6.47 & 0.10 & 102 & 6.12 & 0.15 & 0.02 & 349 & 6.3 & 0.08 & 326 & 6.2 & 0.07 & NS \\
\hline $\begin{array}{l}\text { Sleep duration } \\
9 \mathrm{mth}(\mathrm{h})\end{array}$ & 338 & 11.2 & 0.12 & 97 & 11.0 & 0.16 & NS & 698 & 11.4 & 0.1 & 498 & 11.2 & 0.1 & 0.01 \\
\hline $\begin{array}{l}\text { Sleep duration } \\
18 \text { mth (h) }\end{array}$ & 326 & 11.3 & 0.17 & 91 & 11.6 & 0.22 & NS & 641 & 11.6 & 0.1 & 481 & 11.4 & 0.1 & 0.03 \\
\hline
\end{tabular}

*ANCOVA adjusting for measurement at 12 weeks, weaning behaviour (solids $\leqslant 12$ weeks $v>12$ weeks), milk feeding (breast $v$ formula), gender, and (for term infants) whether AGA or SGA. Adjusted means are shown.

gain between 12 weeks and 18 months were greater in boys than in girls, and these differences remained after adjusting for social factors. No gender effects were observed for atopy (eczema, wheeze, asthma), LRTI, gastroenteritis, or sleep or wake patterns.

\section{Cohort effect}

Table 4 shows the influence of size for gestation at birth in term infants (AGA verses SGA). Length gain and head circumference gain between birth and 18 months were greater in the SGA compared with the AGA subjects. When the model was adjusted for social factors, the length difference remained significant but the head circumference difference disappeared. SGA infants were significantly shorter than AGA infants at 12 weeks and it is likely that the observed greater length gain represents catch up growth.

No cohort effects were observed for atopy (eczema, wheeze, asthma), LRTI, gastroenteritis, or sleep duration. However, SGA infants were significantly more likely to wake during the night at 18 months (38\% SGA versus 32\% AGA infants reported as waking at night, $\mathrm{p}<0.05$ ).

\section{Preterm infants}

Weaning before or after 12 weeks

There was no significant difference in weight, length, or head circumference gain between 12 weeks and 9 months post- term in infants weaned before or after 12 weeks. Those weaned before 12 weeks showed significantly greater gain in subscapular skinfold thickness, but not triceps skinfold thickness (table 1).

Analysis of growth between 12 weeks and 18 months postterm in the cohort $(n=415)$ of infants followed to this age showed no effect of weaning age on weight, length, or head circumference gain over this period.

Infants weaned before 12 weeks were heavier $(5.38 \mathrm{~kg} v$ $5.09 \mathrm{~kg}, \mathrm{p}=0.001)$ and longer $(58.04 \mathrm{~cm} v 57.04 \mathrm{~cm}$, $\mathrm{p}=0.03)$ at this age than those who were not, and they remained heavier $(p=0.03)$, although not significantly longer at 9 months post-term. By 18 months post-term, there were no significant differences in weight or length between weaning groups.

There was no evidence for an effect of weaning behaviour on atopy, LRTI, gastroenteritis, sleep duration, or waking at night. By 9 months, $21 \%$ of infants were reported to have developed eczema, $8 \%$ had asthma, and $21 \%$ had had at least one episode of diarrhoea. By 18 months, 31\% had eczema, $15 \%$ asthma, and $29 \%$ had had at least one episode of diarrhoea since the 9 month visit.

In a univariate analysis, males were weaned earlier than females in preterm infants, though this was not statistically significant at the $5 \%$ level $\left(50.6 \% \vee 49.4 \%\right.$ respectively, $\chi^{2}$ test, $\mathrm{p}=0.136)$. When adjusted for weight, in a multivariate

Table 2 Influence of type of milk feeding (breast feeding for 6 weeks or formula fed) on growth and sleep patterns; measurements at 9 months in preterm infants and 18 months in term infants adjusted for measurements at 12 weeks*

\begin{tabular}{|c|c|c|c|c|c|c|c|c|c|c|c|c|c|c|}
\hline & \multicolumn{7}{|c|}{ Preterm infants } & \multicolumn{7}{|c|}{ Term infants } \\
\hline & \multicolumn{3}{|c|}{ Breast feeders } & \multicolumn{3}{|c|}{ Formula feeders } & \multirow[b]{2}{*}{$\mathbf{p}$} & \multicolumn{3}{|c|}{ Breast feeders } & \multicolumn{3}{|c|}{ Formula feeders } & \multirow[b]{2}{*}{$\mathbf{p}$} \\
\hline & $\mathrm{n}$ & Mean & SE & $\mathrm{n}$ & Mean & SE & & n & Mean & SE & $\mathrm{n}$ & Mean & SE & \\
\hline Weight gain (kg) & 58 & 8.31 & 0.09 & 409 & 8.21 & 0.04 & NS & 234 & 10.9 & 0.06 & 442 & 10.7 & 0.05 & 0.001 \\
\hline Length gain $(\mathrm{cm})$ & 58 & 70.5 & 0.28 & 406 & 70.5 & 0.13 & NS & 234 & 81.4 & 0.16 & 443 & 80.9 & 0.12 & 0.01 \\
\hline $\begin{array}{l}\text { Head circumference } \\
\text { gain }(\mathrm{cm})\end{array}$ & 58 & 45.8 & 0.15 & 408 & 45.8 & 0.07 & NS & 236 & 48.3 & 0.06 & 444 & 47.9 & 0.05 & 0.001 \\
\hline $\begin{array}{l}\text { Triceps skinfold } \\
\text { gain }(\mathrm{mm})\end{array}$ & 58 & 8.26 & 0.29 & 408 & 9.04 & 0.13 & 0.01 & 234 & 9.1 & 0.15 & 442 & 8.6 & 0.11 & 0.01 \\
\hline $\begin{array}{l}\text { Subscapular skinfold } \\
\text { gain (mm) }\end{array}$ & 58 & 6.40 & 0.18 & 408 & 6.19 & 0.08 & NS & 233 & 6.3 & 0.09 & 442 & 6.2 & 0.06 & NS \\
\hline $\begin{array}{l}\text { Sleep duration } \\
9 \mathrm{mth}(\mathrm{h})\end{array}$ & 30 & 11.2 & 0.2 & 405 & 11.0 & 0.07 & NS & 413 & 11.2 & 0.1 & 774 & 11.4 & 0.06 & 0.01 \\
\hline $\begin{array}{l}\text { Sleep duration } \\
18 \mathrm{mth}(\mathrm{h})\end{array}$ & 26 & 11.5 & 0.32 & 393 & 11.5 & 0.1 & NS & 391 & 11.5 & 0.08 & 731 & 11.6 & 0.06 & NS \\
\hline
\end{tabular}

*ANCOVA adjusting for measurement at 12 weeks, weaning behaviour (solids $\leqslant 12$ weeks $v>12$ weeks), milk feeding (breast $v$ formula), gender, and (for term infants) whether AGA or SGA. Adjusted means are shown. 
Table 3 Gender effect on growth and sleep patterns; measurements at 9 months in preterm infants and 18 months in term infants adjusted for measurements at 12 weeks*

\begin{tabular}{|c|c|c|c|c|c|c|c|c|c|c|c|c|c|c|}
\hline & \multicolumn{7}{|c|}{ Preterm infants } & \multicolumn{7}{|c|}{ Term infants } \\
\hline & \multicolumn{3}{|c|}{ Males } & \multicolumn{3}{|c|}{ Females } & \multirow[b]{2}{*}{$\mathrm{p}$} & \multicolumn{3}{|c|}{ Males } & \multicolumn{3}{|c|}{ Females } & \multirow[b]{2}{*}{$\mathbf{p}$} \\
\hline & $\mathrm{n}$ & Mean & SE & $n$ & Mean & SE & & $\mathbf{n}$ & Mean & SE & $n$ & Mean & SE & \\
\hline Weight gain (kg) & 224 & 8.35 & 0.06 & 243 & 8.17 & 0.06 & 0.007 & 343 & 10.9 & 0.05 & 333 & 10.7 & 0.05 & 0.002 \\
\hline Length gain $(\mathrm{cm})$ & 222 & 71.0 & 0.19 & 242 & 70.0 & 0.19 & $<0.001$ & 344 & 81.3 & 0.14 & 333 & 80.1 & 0.14 & 0.03 \\
\hline $\begin{array}{l}\text { Head circumference } \\
\text { gain }(\mathrm{cm})\end{array}$ & 224 & 46.0 & 0.1 & 242 & 45.6 & 0.10 & $<0.001$ & 345 & 48.3 & 0.06 & 335 & 48.0 & 0.06 & 0.001 \\
\hline $\begin{array}{l}\text { Triceps skinfold } \\
\text { gain }(\mathrm{mm})\end{array}$ & 223 & 8.68 & 0.17 & 243 & 8.61 & 0.23 & NS & 341 & 8.8 & 0.12 & 335 & 8.9 & 0.13 & NS \\
\hline $\begin{array}{l}\text { Subscapular } \\
\text { skinfold gain (mm) }\end{array}$ & 223 & 6.24 & 0.12 & 243 & 6.35 & 0.11 & NS & 341 & 6.2 & 0.07 & 334 & 6.3 & 0.08 & NS \\
\hline $\begin{array}{l}\text { Sleep duration } \\
9 \mathrm{mth} \text { (h) }\end{array}$ & 210 & 11.1 & 0.14 & 225 & 11.2 & 0.13 & NS & 612 & 11.3 & 0.07 & 575 & 11.3 & 0.07 & NS \\
\hline $\begin{array}{l}\text { Sleep duration } \\
18 \text { mth (h) }\end{array}$ & 201 & 11.5 & 0.19 & 218 & 11.5 & 0.18 & NS & 582 & 11.5 & 0.7 & 540 & 11.6 & 0.07 & NS \\
\hline
\end{tabular}

*ANCOVA adjusting for measurement at 12 weeks, weaning behaviour (solids $\leqslant 12$ weeks $v>12$ weeks), milk feeding (breast $v$ formula), gender, and (for term infants) whether AGA or SGA. Adjusted means are shown.

analysis, gender was not a significant predictor of weaning age. $^{7}$

\section{Milk feeding}

Breast fed preterm infants showed significantly lower gain in triceps skinfold thickness between 12 weeks and 9 months, but no other growth differences were apparent in breast versus formula fed infants over this period (table 2). However, breast fed infants were significantly lighter and shorter at 12 weeks than formula fed infants and remained lighter $(p=0.02)$ and shorter $(p=0.06)$ at 9 months postterm. Sleep duration and waking at night were similar in both groups at 9 and 18 months.

\section{Gender}

Preterm boys showed significantly greater gains in weight, length, and head circumference between 12 weeks and 9 months than preterm girls (table 3 ).

\section{DISCUSSION}

There is increasing evidence that events early in life such as growth rate and type of milk feeding may have long term consequences for health. For example, it has been shown in a number of animal models as well as in humans, that growth promotion during infancy may predispose the individual to an increased risk of high blood pressure, ${ }^{9}$ obesity, ${ }^{10}$ noninsulin dependent diabetes, ${ }^{11}$ and ischaemic heart disease later in life. ${ }^{12}$ Most data relating to infant feeding have examined the effect of the type of milk used, and the effect of introducing solid foods has been relatively neglected.
However, it is clearly important that, in addition to considering potential short term effects of weaning such as the risk of infection or atopy, effects beyond infancy are examined.

We have used existing data collected prospectively in a number of infant feeding trials during the mid to late 1990s to investigate the effects of the timing of introduction of solids on outcome up to 18 months post-term. ${ }^{7}$ Although our studies were not designed primarily to investigate the effects of weaning, data on growth, health, and sleep patterns were recorded for all infants prospectively and in a systematic manner. This has allowed us to examine the influence of age of solid food introduction on these outcomes. Our studies were conducted in the UK, and our results may not, therefore, be generalisable to infants reared in developing countries.

As reported previously by us, and in line with contemporaneous findings from the UK Infant Feeding Survey, ${ }^{13}$ a significant proportion of infants in our studies were already receiving solids by 12 weeks and even 6 weeks of age. ${ }^{7}$ This is despite the $\mathrm{DOH}^{14}$ recommendation at that time that solids should not be introduced before 4 months for the majority of infants.

\section{Term infants}

Infants who received solids at or before 12 weeks were heavier at 12 weeks of age as reported previously. ${ }^{71} 16$ However, they showed slower gain in weight, length, and head circumference between 12 weeks and 18 months. Thus, at 18 months of age, there were no significant differences in

Table 4 Influence of cohort effect on growth and sleep patterns assessed at 18 months in term infants*

\begin{tabular}{|c|c|c|c|c|c|c|c|}
\hline & \multicolumn{3}{|l|}{ SGA } & \multicolumn{3}{|l|}{ AGA } & \multirow[b]{2}{*}{$\mathbf{p}$} \\
\hline & $\mathbf{n}$ & Mean & SE & $\mathbf{n}$ & Mean & SE & \\
\hline Weight gain (kg) & 337 & 10.79 & 0.06 & 339 & 10.8 & 0.06 & NS \\
\hline Length gain $(\mathrm{kg})$ & 338 & 81.4 & 0.15 & 339 & 80.9 & 0.15 & 0.03 \\
\hline $\begin{array}{l}\text { Head circumference } \\
\text { gain }(\mathrm{cm})\end{array}$ & 339 & 48.3 & 0.06 & 341 & 48.0 & 0.06 & 0.001 \\
\hline Triceps skinfold gain $(\mathrm{cm})$ & 337 & 8.8 & 0.12 & 339 & 8.9 & 0.13 & NS \\
\hline $\begin{array}{l}\text { Subscapular skinfold } \\
\text { gain }(\mathrm{mm})\end{array}$ & 337 & 6.2 & 0.07 & 338 & 6.3 & 0.08 & NS \\
\hline Sleep duration $9 \mathrm{mth}(\mathrm{h})$ & 359 & 11.2 & 0.08 & 828 & 11.4 & 0.06 & NS \\
\hline Sleep duration $18 \mathrm{mth}(\mathrm{h})$ & 342 & 11.5 & 0.08 & 780 & 11.6 & 0.06 & NS \\
\hline
\end{tabular}

*ANCOVA adjusting for measurement at 12 weeks, weaning behaviour (solids $\leqslant 12$ weeks $v>12$ weeks), milk feeding (breast $v$ formula), gender, and (for term infants) whether AGA or SGA. Adjusted means are shown. 
size between the two groups. This suggests that earlier weaning was not associated with a greater risk of the infants becoming overweight during infancy. Similar findings were reported by Forsyth and colleagues. ${ }^{15}$ Infants who received solids before 12 weeks were significantly heavier at 4, 8, 13, and 26 weeks than those who received solids after 12 weeks, but there were no differences in weights at 1 and 2 years of age. $^{15}$

Interestingly, breast fed infants showed greater gain in weight, length, head circumference, and triceps skinfold thickness between 12 weeks and 18 months than formula fed infants. Breast fed infants were lighter than formula fed infants at 12 weeks, so the greater weight gain by 18 months may reflect a degree of "catch up". Weight gain between 12 weeks and 9 months was similar in breast and formula fed infants, and the "catch up" occurred between 9 and 18 months. It seems unlikely that this reflects milk feeding. The effect remained after adjusting for available socioeconomic factors. However, it could still be the result of an unmeasured confounding factor such as parental size. This is supported by the fact that length and head circumference also appear to show acceleration in the breast fed group between 9 and 18 months.

Term SGA infants showed greater length and head circumference gains than AGA infants. Length differences remained after adjusting for confounding factors. Since the SGA infants were shorter at 12 weeks than AGA infants, this pattern is likely to reflect catch up growth. Previous studies in SGA infants have suggested that the window for catch up in length extends throughout the first 6-9 months, whereas that for weight seems to occur earlier, possibly explaining why weight gain between 12 weeks and 18 months was similar in both cohorts, since weight catch up had already occurred.

Infants weaned before 12 weeks were reported to be sleeping for longer at both 9 and 18 months. However, the difference amounted to an extra 12 minutes on average per night, and it is difficult to regard this as either biologically or practically important. Moreover, the difference was no longer significant after adjusting for potential socioeconomic confounding factors. Breast fed infants who were weaned before 12 weeks of age were more likely to sleep through the night at 9 months than those weaned after 12 weeks. This may well be because the latter group are more likely to still be breast fed at 9 months and therefore waking to feed. We were unable to investigate this issue further as no details were collected on the reason(s) for infants waking. Formula fed infants were reported to be sleeping for approximately 12 minutes per night longer at 9 months than breast fed infants, and this finding remained significant after adjusting for confounding factors. Interestingly, sleep duration at 26 weeks (when more of the breast fed group were likely to have been still breast feeding) was similar in breast and formula fed infants, suggesting that the apparent difference between the groups at 9 months may reflect unmeasured social or behavioural confounding factors.

We found no evidence that weaning before or after 12 weeks influenced the likelihood of the infant developing gastroenteritis or atopy. Wilson et al reported that introduction of solids before 15 weeks was associated with a significantly greater probability of developing wheeze by age 7 years. However, it is possible that such an effect would become apparent in our cohorts with longer follow up. Fergusson and colleagues ${ }^{17}$ reported that exposure to more than four foods before 4 months of age in full term infants was associated with a 2.9-fold increase in the risk of eczema at 10 years of age, suggesting that possibly the nature rather than simply the timing of solid feeding may be important, although no effect of solid feeding on eczema had been seen at 2 year follow up of the same cohort. Interestingly in a cohort of preterm infants, exposure to more than four foods before 4 months of age was associated with an increased risk of eczema (odds ratio 3.49) at the much earlier age of 12 months post-term. ${ }^{18}$

\section{Preterm infants}

Preterm infants weaned $\leqslant 12$ weeks were significantly heavier and longer at 12 weeks than later weaned infants. However, subsequent growth rates up to 9 months post-term did not differ significantly between the two groups, apart from greater gain in subscapular skinfold thickness in the earlier weaned group. Early weaned infants therefore remained significantly heavier than later weaned infants at 9 months. However, by 18 months post-term there were no significant differences between groups suggesting that, as with the term infants, there had been "catch up" in the later weaned infants.

Breast fed preterm infants were significantly lighter and shorter than formula fed infants at 12 weeks of age, but growth between 12 weeks and 9 months was not significantly different in the two groups apart from lower subscapular skinfold thickness gain in the breast fed infants. Thus, breast fed infants remained lighter and shorter than formula fed infants at 9 months post-term. Unfortunately, the number of breast fed infants followed up to 18 months $(n=24)$ was insufficient to permit comparison of growth between breast and formula fed infants during this period.

\section{Conclusion}

The effects of introducing solids before or after 12 weeks on growth and health outcomes during infancy were limited. Growth data from both term and preterm infants suggested that there were size differences at 12 weeks of age in infants who were or were not weaned at this point, and that these differences had largely disappeared by 18 months post-term, due predominantly to catch up between 9 and 18 months.

Overall our findings suggest that larger infants, whether term or preterm, are more likely to be given solids by 12 weeks, but that this does not result in accelerated growth, at least during infancy. It is possible that the apparent convergence in size between 9 and 18 months reflects the influence of genetic factors such as parental size. Unfortunately, this was not systematically recorded in all our studies and we were unable to investigate this possibility. However, even if there are no apparent differences in size at 18 months in relation to the introduction of solid foods before or after 12 weeks, this does not preclude the later emergence of programmed effects. Wilson and colleagues ${ }^{19}$ reported increased body weight and body fatness at age 7 years in children who had received solids before 15 weeks, although there had been no apparent effect on weight at 2 year follow up. Marriott and colleagues $^{20}$ in the only randomised control trial of age of weaning in the West showed that earlier weaning increased length velocity to one year and haemoglobin at 6 months in preterm infants. Furthermore, Lewis and colleagues ${ }^{10}$ reported that baboons overfed for a brief period during infancy became obese during adolescence following a period of normal body weight during childhood. The collection of follow up data during childhood for our cohorts will allow us to look for any late emerging programmed effects of weaning behaviour.

\section{Authors' affiliations}

J B Morgan, School of Biomedical and Molecular Sciences, University of Surrey, Guildford, Surrey GU2 7XH, UK

A Lucas, M S Fewtrell, MRC Childhood Nutrition Research Centre, Institute of Child Health, 30 Guilford Street, London WCIN 1EH, UK 


\section{REFERENCES}

1 Kramer MS, Kakuma R. The optimal duration of exclusive breast feeding. A systematic review. Department of Nutrition for Health and Development. Geneva: World Health Organisation, 2001.

2 World Health Organisation. Infant and young child nutrition. Geneva: Fiftyfourth World Health Assembly, 2001:54.2.

3 Lucas A, Stafford M, Morley R, et al. Efficacy and safety of long-chain polyunsaturated fatty acid supplementation of infant-formula milk: a randomised trial. Lancet 1999;354:1948-54.

4 Morley R, Abbott R, Fairweather-Tait S, et al. Iron fortified follow on formula from 9 to 18 months improves iron status but not development or growth: a randomised trial. Arch Dis Child 1999;81:247-52.

5 Fewtrell MS, Morley R, Abbott RA, et al. Catch-up growth in small for gestational age term infants: a randomised trial. AJCN 2001;74:516-23.

6 Lucas A, Fewtrell MS, Abbott RA, et al. Randomised trial of nutrient enriched formula versus standard formula for post-discharge preterm infants. Pediatrics 2001; 108:703-11.

7 Fewtrell MS, Lucas A, Morgan JB. Factors associated with the age of introduction of solid foods in full term and preterm infants. Arch Dis Child Fetal Neonatal Ed 2003;88:F296-302.

8 Lucas A, Morley R, Cole TJ, et al. Mother's choice to provide breast milk and developmental outcome. Arch Dis Child 1988;63:1382-5.

9 Langley-Evans SC, Welham SG, Jackson AA. Fetal exposure to a maternal low protein diet impairs nephrogenesis and promotes hypertension in the rat Life Sci 1999;64:965-74.
10 Lewis DS, Bartrand HA, McMahan CA, et al. Preweaning food intake influences the adiposity of young adult baboons. J Clin Invest 1996;78:899-905

11 Hales CN. Early programming of glucose metabolism, insulin action and longevity. Adv Exp Med Biol 2000;478:57-64

12 Mott GE, Lewis DS, McGill HC Jr. Programming of cholesterol metabolism by breast or formula feeding. CIBA Foundation Symposium 1991;156:56-66.

13 Hamlyn B, Brooker S, Oleinikova K, et al. Infant feeding 2000. London: TSO, 2002.

14 Department of Health. Weaning and the weaning diet. Report on Health and Social Subjects no. 46. London: HMSO, 1994.

15 Forsyth JS, Ogston SA, Clark A, et al. Relation between early introduction of solid food to infants and their weight and illnesses during the first two years of life. BMJ 1993;306:1572-6.

16 Savage SAH, Reilly JJ, Edwards CA, et al. Weaning practice in the Glasgow longitudinal infant growth study. Arch Dis Child 1998;79:153-6.

17 Fergusson DM, Horwood $\sqcup$, Shannon FT. Early solid feeding and recurrent childhood eczema: a 10-year longitudinal study. Pediatrics 1990;86:541-6.

18 Morgan JB, Williams P, Norris F, et al. Eczema and early solid feeding in preterm infants. Arch Dis Child 2004;89:309-14.

19 Wilson A, Stewart Forsyth J, Greene SA, et al. Relation of infant diet to childhood health: seven year follow up of cohort of children in Dundee infant feeding study. BMJ 1998:316:21-5.

20 Marriott LD, Foote KD, Bishop JA, et al. Preterm infants post-discharge growth in length improves with a novel nutritional strategy. Arch Dis Child Fetal Neonatal Ed 2003;88:F302-7. 